\title{
Pagamento de serviço ambiental, valor justo e valor de mercado: um estudo tipológico de uma companhia do segmento de papel e celulose
}

\author{
Payment for environmental service, fair value and market value: a typological study of a company
}

in the pulp and paper segment

Pago por servicio ambiental, valor justo y valor de mercado: un estudio tipológico de una empresa en el segmento de celulosa y papel

\section{Resumo}

O Pagamento de Serviços Ambientais tornou-se lei (14.119/21) em 2021, portanto um marco se instala no tratamento aspectos ambientais relevantes. Neste contexto a qualidade da informação ambiental deve ser observada como uma linguagem dos negócios no âmbito internacional. Sendo assim, a presente pesquisa busca investigar: busca compreender qual o alinhamento tipológico aplicada nos textos da Lei 14.119/21 em relação ao arcabouço teórico sobre a norma IFRS que trata de valor justo: Valor justo CPC 46 - Mensurações do Valor Justo (instrumentos financeiros); IFRS 13 Fair Value Measurement e Ativos biológicos (plantas e animais) CPC 29 - IAS 41. Por metodologia, utilizou-se o estudo de casos tendo a Klabin S.A como objeto e também foi realizada uma análise do tipo documental no texto da Lei de pagamento de serviços ambientais (PSA) e do relatório trimestral de uma empresa potencialmente poluidora do segmento de papel e celulose. Através das discussões e dos resultados, foi possível verificar que alguns aspectos relativos à informação financeira (valor justo e valor de mercado) não foram levados em conta no texto redacional da Lei supracitada. Observou-se também que a Lei do PSA delineia mais questões ambientais do que as observadas pela empresa em tela.

Palavras-chave: Valor justo; Valor de mercado; Ativos biológicos; Lei 14.119/21.

\begin{abstract}
Payment for Environmental Services became law (14,119/21) in 2021, so a milestone is installed in the treatment of relevant environmental aspects. In this context, the quality of environmental information must be seen as a business language at the international level. Therefore, this research seeks to investigate: it seeks to understand the typological alignment applied in the texts of Law 14.119/21 in relation to the theoretical framework on the IFRS standard that deals with fair value: Fair value CPC 46 - Fair Value Measurements (financial instruments); IFRS 13 Fair Value Measurement and Biological Assets (Plants and Animals) CPC 29 - IAS 41. For methodology, case studies were used with Klabin SA as the object and an analysis of the document type was also carried out in the text of the Payment Law environmental services (PSA) and the quarterly report of a potentially polluting company in the pulp and paper segment. Through the discussions and the results, it was possible to verify that some aspects related to financial information (fair value and market value) were not taken into account in the wording of the aforementioned Law. It was also observed that the PES Law outlines more environmental issues than those observed by the company in question.
\end{abstract}

Keywords: Fair value; Market value; Biological assets; Law 14.119/21.

\section{Resumen}

El Pago por Servicios Ambientales se convirtió en ley (14.119 / 21) en 2021, por lo que se instala un hito en el tratamiento de los aspectos ambientales relevantes. En este contexto, la calidad de la información ambiental debe verse como un lenguaje comercial a nivel internacional. Por tanto, esta investigación busca investigar: busca comprender la alineación tipológica aplicada en los textos de la Ley 14.119 / 21 en relación con el marco teórico de la norma NIIF que trata del valor razonable: Valor razonable CPC 46 - Mediciones del valor razonable (financiero instrumentos); NIIF 13 Medición del Valor Razonable y Activos Biológicos (Plantas y Animales) CPC 29 - NIC 41. Para la metodología se utilizaron estudios de caso con Klabin SA como objeto y también se realizó un análisis del tipo de documento en el texto de la Ley de Pagos. servicios ambientales (PSA) y el informe trimestral de una empresa 
potencialmente contaminante en el segmento de celulosa y papel. A través de las discusiones y los resultados se pudo constatar que algunos aspectos relacionados con la información financiera (valor razonable y valor de mercado) no fueron tomados en cuenta en la redacción de la referida Ley. También se observó que la Ley de PSA traza más cuestiones ambientales que las observadas por la empresa en cuestión.

Palabras clave: Valor razonable; Valor comercial; Activos biológicos; Ley 14.119/21.

\section{Introdução}

O Plano de Pagamento de Serviços Ambiental (PSA) tem por objetivo delinear o tema instrumento econômico para a proteção ambiental, bem como a visão sistemática de gestão ambiental descrita na constituição Federal que estabelece a responsabilidade compartilhada entre o poder público e a coletividade pela manutenção do meio ambiente ecologicamente atribuído ao Ministério Público.

Dentre os instrumentos econômicos está o PSA que oferece incentivos positivos para as práticas de recuperação, manutenção e melhoria nos serviços sistêmicos descrito no Código Florestal e no regulamento da Política Nacional dos Resíduos Sólidos - PNRS.

A nova política ambiental tem como finalidade a elaboração do manual (PPSA) nas seguintes perspectivas: serviços ecossistêmicos e instrumentos econômicos e PSA. Observa-se primeiramente a elaboração da classificação dos serviços ecossistêmicos relevantes para delinear as principais categorias: serviços de provisão (madeira, água, alimentos), serviços reguladores (clima, controle de doença), serviços de suporte (ciclo da água e formação do solo) e serviços culturais (atividades espirituais e recepcionais).

O manual (PPSA) apresenta os serviços ecossistêmicos relacionados aos ambientes existentes: tratamento de efluentes, produção de alimentos, sequestra de carbono, regulação do clima e turismo e recreação (Marinho). Destaque para os ambientes florestais, campos, áreas úmidas, lagos e rios.

É mister observar, que o PSA tornou-se recentemente, Lei (14.119/21), e que ainda é desconhecida suas práticas da maioria das empresas atuantes no país. É relevante assinalar que para o processo de precificação das questões relativas aos serviços de natureza ambiental, é oferecido incentivos para as empresas no contexto ambiental. Não obstante, a questão de valoração de preço, deve ser observada na perspectiva de mercado, a criação da necessidade de pesquisa no campo da tipologia sobre valor de mercado e PSA. Correlacionar estes conceitos, torna-se critérios de avaliação de impacto ambiental uma ferramenta relevante no processo decisório.

Nessa perspectiva a cobrança pelo uso da água, o uso de telhado verde, mercado de crédito de carbono enfatizam a aplicação do PSA, estabelecendo os limites de emissões. Assim, os aspectos levantados pelos instrumentos econômicos são eficazes em situações que oferecem benefícios para incrementar os ecossistemas: água, solo para proteger espécies nativas, por meio do reflorestamento, recuperação, tratamento de água.

As normas contábeis, regras e leis, alteram os custos e os benefícios dos diversos cursos de ações. Os rótulos voluntários e obrigatórios são frequentes escolhas contábeis. Os padrões das políticas contábeis evidenciado pela história da contabilidade para crédito tributário de investimento, depreciação, estoques, gastos com a exploração de petróleo e gás e compensação de empregados baseados em ações (Sander, 2004).

Para Paulo e Leme (2007) os accruals discricionários (são proxies para os comportamentos oportunísticos dos gestores) e os resultados obtidos verificaram que as companhias abertas que obtiveram prejuízos e/ou grande variabilidade nos resultados postergaram a publicação das demonstrações contábeis e divulgaram após o prazo estabelecido pela regulação contábil pertinente.

Cabe ressaltar que o PSA é uma política voluntária da empresa, demonstrando uma predisposição da empresa para mudança de comportamento, mudança de atitude, mentalidade dos gestores voltadas para ações menos poluidoras. Contudo, a 
grande fragilidade diz respeito à gestão pública quanto à origem dos recursos destinados para ações mitigadoras quanto ao dano Ambiental. Assim nasce o problema desta pesquisa: Quais as tipologias utilizadas na Lei 14.119/21 e no Relatório Trimestral (ITR agosto de 2021) sobre PSA, valor justo e valor de mercado de uma empresa no segmento de papel e celulose no Brasil? . Portanto, o objetivo do estudo foi compreender qual o alinhamento tipológico aplicada nos textos da Lei 14.119/2 1 em relação ao arcabouço teórico sobre a norma IFRS que trata de valor justo: Valor justo CPC 46 - Mensurações do Valor Justo (instrumentos financeiros); IFRS 13 Fair Value Measurement e Ativos biológicos (plantas e animais) CPC 29 - IAS 41.

\section{Estado Teórico da Arte Contemporâneo}

Os conceitos fundamentais da contabilidade podem ser interpretados na linguagem das ciências sociais tais como entidade, avaliação monetária, competência e uniformidade, reduzindo consideravelmente a confusão de categorias, tais como postulados, princípios, doutrinas e características da contabilidade, em uma classificação mais simples de convenções e características econômicas. Os conceitos como uniformidade e comparabilidade devem ser observados para a informação contábil (Sunder, 2014).

A aplicação do valor justo e os estudos sobre sua aplicação não são recentes, principalmente nos Estados unidos da América, por meio do IASB (International Accounting Standards Boards). No Brasil este critério foi introduzido nas instituições financeiras em 2001-2002 pelo Banco central para as operações com derivativos e títulos e valores mobiliários. Em 2007 com a alteração da Lei das sociedades anônimas passaram adotar o padrão valor justo semelhante ao ocorrido na Europa em 2005. (Marques, Schultz, Dandolini \& Petri, 2012).

Para Braga, Sousa e Alves Filho (2015) as discussões dos conceitos de ativos e sua mensuração são tratados por Martins (2000) e Hendriksen e Van Breda (2012); que o critério de mensuração de mercado não é assunto atual com base no SFAS 133 (Accounting for derivative Instruments and hedging Activities) que trata de contabilidade de derivativo e outros instrumentos financeiros, mensuração, julgamento, subjetividade (Lopes \& Martins, 2012; Iudicibus \& Martins, 2007).

Braga e Souza (2012) tratam sobre a preocupação em relação do entendimento conceitual e dos fundamentos práticos do valor justo. Observar que existem críticas do valor justo em contextos econômicos específicos, como os de crise financeira, e o uso de julgamento e subjetivismo, que não são comuns no contexto contábil brasileiro, podendo levar práticas indevidas. Então a necessidade de maior debate no âmbito científico e o não rompimento brusco com métodos baseados em custo histórico.

No que diz respeito ao PSA, o estudo de Garrido et. al., (2021) trata da conjectura atual do ICMS-E como ferramenta de gestão ambiental demostrando a eficiência das políticas necessidade de um dispositivo legal que regulamente o desenvolvimento sustentável do estado da Paraíba. Neste sentido, o estudo reforça que estimular e adotar posturas de proteção dos serviços ecossistêmicos é relevante para minimizar a falha de mercado em não recompensar os provedores de serviços ambientais.

Não obstante, a consciência da natureza da ameaça ainda é muito limitada. Esta é a era de especialistas: cada um deles enxerga seu próprio problema e não tem consciência do quadro maior em que ele se encaixa, ou se recusa a apreciá-lo. Também uma era dominada pela indústria, em que ganhar a qualquer custo. É à população que assume os riscos e precisa decidir se deseja continuar no caminho atual (Carson, 2010).

Assim, em 2021, a aprovação da Lei 14.119/21 vem a dirimir a ausência de regulamentação ambiental, bem como criar mecanismo tributário de gestão ambiental para fomentar a conservação e preservação do meio ambiente. Neste sentido fazer um estudo tipológico busca observar se o arcabouço teórico do valor justo e valor de mercado estão alinhados com o texto da Lei PSA. No Quadro 1 trata de pesquisas científicas sobre o segmento estudado. 
Quadro 1. Estudos correlatos ao estudo de caso.

\begin{tabular}{|c|c|c|c|}
\hline \multicolumn{4}{|c|}{ Estudos correlatos ao estudo de caso no âmbito Internacional e Nacional } \\
\hline Estudo & Autores/Ano & Objetivos & Principais resultados \\
\hline $\begin{array}{l}\text { Alianças de poder para } \\
\text { a biodiversidade: } \\
\text { Resultados de um } \\
\text { estudo internacional } \\
\text { sobre a silvicultura } \\
\text { comunitária. }\end{array}$ & $\begin{array}{lcc}\text { Stanzel, } & \text { krott } & \text { e } \\
\text { Schusserb }(2020) . & \end{array}$ & 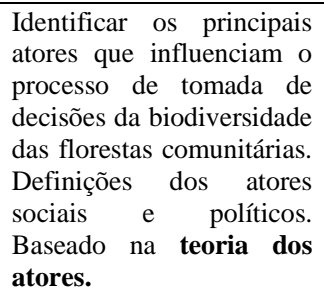 & $\begin{array}{l}\text { Fatores como tamanho, participação e potencial das } \\
\text { florestas estão relacionados ao poder dos atores poderosos } \\
\text { na proteção da biodiversidade da silvicultura comunitária. } \\
\text { Foi realizada uma análise de inter-relação de interesse de } \\
\text { poder denominada de PIDO (Powerful Interest Desired } \\
\text { Outcome): o resultado alto (+1); o resultado intermediário } \\
(1) \text {; o resultado baixo }(-1) \text { e o resultado específico }(0) \text {. }\end{array}$ \\
\hline Ativos Biológicos & Amaral et al. (2015). & $\begin{array}{l}\text { Alcance do CPC 29, } \\
\text { definições e requisitos dos } \\
\text { ativos biológicos. }\end{array}$ & $\begin{array}{l}\text { Variação de preço, valor justo, nível de hierarquia, } \\
\text { premissas de julgamento e reserva de lucro, flutuações de } \\
\text { preço de mercado e fatores associados período } 2009 \text { a } \\
2012 \text {. }\end{array}$ \\
\hline $\begin{array}{l}\text { Divulgação de } \text { ativos } \\
\text { biológicos }- \text { Renar } \\
\text { Maças S.A., Suzano } \\
\text { Papel e Celulose S.A. e } \\
\text { Duratex S.A. }\end{array}$ & $\begin{array}{l}\text { Lemes et. al. } \\
\text { (2014). }\end{array}$ & $\begin{array}{l}\text { Evidenciação das } \\
\text { premissas de valoração. }\end{array}$ & $\begin{array}{l}\text { Evidenciação: o cálculo do valor justo dos ativos } \\
\text { biológicos; estimativas e julgamentos contábeis críticos } \\
\text { (referência de mercado, previsão de eventos futuros, } \\
\text { previsão de contingências e premissas de fluxo de caixa } \\
\text { descontado, preços, diferenciação, volumes e } \\
\text { periodicidade). }\end{array}$ \\
\hline 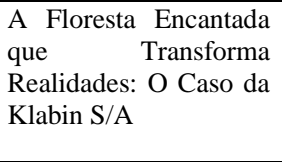 & $\begin{array}{l}\text { Barankievicz, Maria } \\
\text { Sobrinho, } \quad \& \\
\text { Fernandes (2016). }\end{array}$ & $\begin{array}{l}\begin{array}{l}\text { Notas de } \\
\text { Objetivos }\end{array} \\
\begin{array}{l}\text { Ensino, } \\
\text { didáticos, }\end{array} \\
\text { Questões para discussão e } \\
\begin{array}{l}\text { Sugestão de plano de } \\
\text { ensino }\end{array}\end{array}$ & $\begin{array}{l}\text { Pode reforçar a imagem dada Klabin como uma empresa } \\
\text { comprometida com o desenvolvimento sustentável em } \\
\text { seus aspectos ambientais e sociais, além de econômico. }\end{array}$ \\
\hline $\begin{array}{l}\text { Evidenciação } r \\
\text { companhia abertas de } \\
\text { madeira, papel e } \\
\text { celulose no Brasil em } \\
2017 .\end{array}$ & $\begin{array}{l}\text { Melo, Neves \& Luz. } \\
\text { (2019). }\end{array}$ & $\begin{array}{l}\text { Analisar as informações } \\
\text { ambientais dos relatórios } \\
\text { contábeis das companhias } \\
\text { abertas do setor de } \\
\text { madeira, papel e celulose } \\
\text { no Brasil em } \\
\text { conformidade com a NBC } \\
\text { T15, no ano de } 2017 \text {. }\end{array}$ & $\begin{array}{l}\text { As variáveis mais evidenciadas da NBC T15 foram: } \\
\text { Investimentos relacionados ao meio ambiente, } \\
\text { Investimentos relacionados a educação, Investimentos } \\
\text { relacionados a projetos ambientais, Passivos e } \\
\text { contingências ambientais, Políticas ambientais e Outras } \\
\text { informações ambientais. Destaca-se a Irani, Klabin, Fibria } \\
\text { e Duratex foram as empresas que mais evidenciaram em } \\
\text { seus relatórios as subcategorias estudadas. }\end{array}$ \\
\hline
\end{tabular}

Fonte: Autores.

Assim, observa que os estudos descritos no Quadro 1 demostram a relevância da temática reconhecimento e mensuração de valor justo, bem como a norma que trata de ativos biológicos e segmento florestal no âmbito nacional e internacional. Neste sentido, estudar as premissas do arcabouço teórico do valor justo e da lei PSA (recentemente aprovada 2021) ressalta a justificativa do estudo de caso considerando o segmento potencialmente poluidor o setor de papel e celulose.

\section{Metodologia}

Esta pesquisa configura-se como descritiva quanto aos objetivos. De acordo com as especificações do plano de pesquisa utilizada nos estudos descritivos que segundo Richardson (2009) se deseja escrever as características de um fenômeno. Neste sentido, este estudo visa descrever a tipologia do PSA, do valor justo e do valor de mercado do relatório de sustentabilidade ITR, julho de 2021 na perspectiva de responder o problema de pesquisa na empresa Klabin S.A.

A escolha da companhia Klabin S.A foi por se enquadrar nos critérios de empresa potencialmente poluidora conforme o Instituto Brasileiro do Meio Ambiente e dos Recursos Naturais Renováveis - IBAMA (2015), descrito na categoria de Recursos Naturais como atividade florestal e produtos agrícolas. (Tabela de atividades potencialmente poluidoras e utilizadoras de recursos ambientais).

O estudo de caso segundo Yin (2010), significa tratar seus resultados e constatações ao encerramento independente da forma do relatório. Alguns passos similares são subjacentes à composição do estudo de caso: a identificação do público para o relatório, o desenvolvimento de sua estrutura composicional (anexos) e a revisão dos rascunhos por outros (estudos anteriores do Quadro 1).

A companhia foi criada em 1899, as famílias Klabin e Lafer fundaram a companhia Klabin Irmão e Cia. Na década de 1940 a Klabin iniciou o projeto de floresta plantada e introduziu no cenário nacional a produção integrada de papéis 
(Kraftliner, papel cartão e papel reciclado), papelão ondulado e sacos industriais. Atua também no setor florestal com a produção e venda de madeira. Na América Latina é a maior produtora e exportadora de papéis para embalagens (Salotti, Murcia, Carvalho \& Flores, 2015).

Quadro 2. Palavras-chaves relacionadas às tipologias da literatura valoração de mercado.

\begin{tabular}{|c|c|c|c|c|}
\hline $\begin{array}{l}\text { Nível (1, } 2 \text { e } 3) \text { são proxies } \\
\text { para o comportamento } \\
\text { oportuníssimo dos gestores. }\end{array}$ & $\begin{array}{c}\text { Julgamento } \\
\text { (ética) }\end{array}$ & $\begin{array}{c}\text { Premissas } \\
\text { Contábeis (taxa de } \\
\text { desconto) } \\
\end{array}$ & $\begin{array}{l}\text { Test de imparment } \\
\text { Teste de efetividade }\end{array}$ & $\begin{array}{c}\text { Análise de } \\
\text { sensibilidade }\end{array}$ \\
\hline $\begin{array}{c}\text { Valor justo } \\
\text { (subjetivo) }\end{array}$ & $\begin{array}{l}\text { Custo } \\
\text { histórico } \\
\text { (objetivo) }\end{array}$ & Dados observáveis & $\begin{array}{c}\text { Mercado } \\
\text { Marcação de mercado } \\
\text { Marcação de preço de Mercado } \\
\text { Mercado ativo }\end{array}$ & Conservadorismo \\
\hline Relevância & Confiança & Risco & Parece do auditor & $\begin{array}{c}\text { Ativos } \\
\text { Biológicos } \\
\end{array}$ \\
\hline $\begin{array}{l}\text { Segmento florestal (pínus e } \\
\text { eucalípto) }\end{array}$ & $\begin{array}{l}\text { Atividade } \\
\text { Florestas }\end{array}$ & $\begin{array}{l}\text { Produtos } \\
\text { Agrícola }\end{array}$ & $\begin{array}{c}\text { PSA/ Pagamento de Serviços } \\
\text { Ambientais }\end{array}$ & Lei $14.119 / 21$ \\
\hline
\end{tabular}

Fonte: Adaptado dos estudos de Menezes et. al., (2018); Marques et. al., (2012).

Em relação à literatura de valor justo e valor de mercado foi identificado as seguintes palavras na busca relacional com relatório trimestral da empresa objeto de estudo no período de agosto de 2021 (Quadro 2) e do texto da Lei 14.19/21: Ecossistema, Manutenção, Recuperação, Bens e produtos ambientais, Decomposição de resíduos, Sequestro de carbono, Serviços culturais, Pagamento por serviços ambientais, Condições ambientais dos ecossistemas, Certificado de reduções de emissões por desmatamento e degradação, Títulos verde ou green bonds, Comodato, Cota de reserva ambiental, Vegetação nativa, Desenvolvimento sustentável, Qualidade de vida, Biomas, Legislação ambiental, Inclusão socioeconômica e a regularização ambiental de populações rurais em situação de vulnerabilidade, Formação de corredores de biodiversidade, Conservação de recursos hídricos, Comunidades, povos indígenas, agricultores familiares e empreendedores rurais, Financiamentos e agências bilaterais e multilaterais, Conservação de áreas urbanas, periurbanas e qualidade do ar.

O critério da escolha do ITR -Klabin diz respeito às informações financeiras relevantes para os usuários externos, acreditando que, as variáveis desta pesquisa encontram-se de forma mais presente, não desconsiderando aqui a qualidade informacional do relatório de sustentabilidade.

Para realizar o estudo tipológico foi analisada a descrição textual das informações financeiras (informações trimestrais agosto de 2021) da empresa objeto de estudo com a busca de palavras que permeiam o objeto de estudo desta pesquisa. Para Richardson (2009) a análise documental visa estudar e analisar um ou vários documentos para descobrir às circunstancias sociais e econômicas com os quais podem estar relacionados.

\section{Resultados e Discussão}

O modelo de negócios da Companhia Klabin segrega-se três segmentos: florestal, papéis e de conversão. A colheita dos pínus e dos eucaliptos, 14 anos e 7 anos respectivamente, abastecendo as fábricas de papéis e venda de madeiras(toras) para terceiros no mercado interno. O reconhecimento e mensuração de ativos biológicos na Klabin pelo custo histórico (Pínus até sete anos eucalipto até três anos) e o valor justo se refere à projeção de fluxo de caixa futuro (Salotti et. al., 2015).

De acordo com a Figura 1 observa as principais práticas de gestão ambiental, descrição do vídeo institucional da Klabin, uso da tecnologia de monitoramento, centro de tecnologia e sistema integrado de gestão e produção e venda. 
Figura 1. Monitoramento e Gestão Integrada da Companhia Klabin S.A (dados institucionais da empresa objeto de estudo).

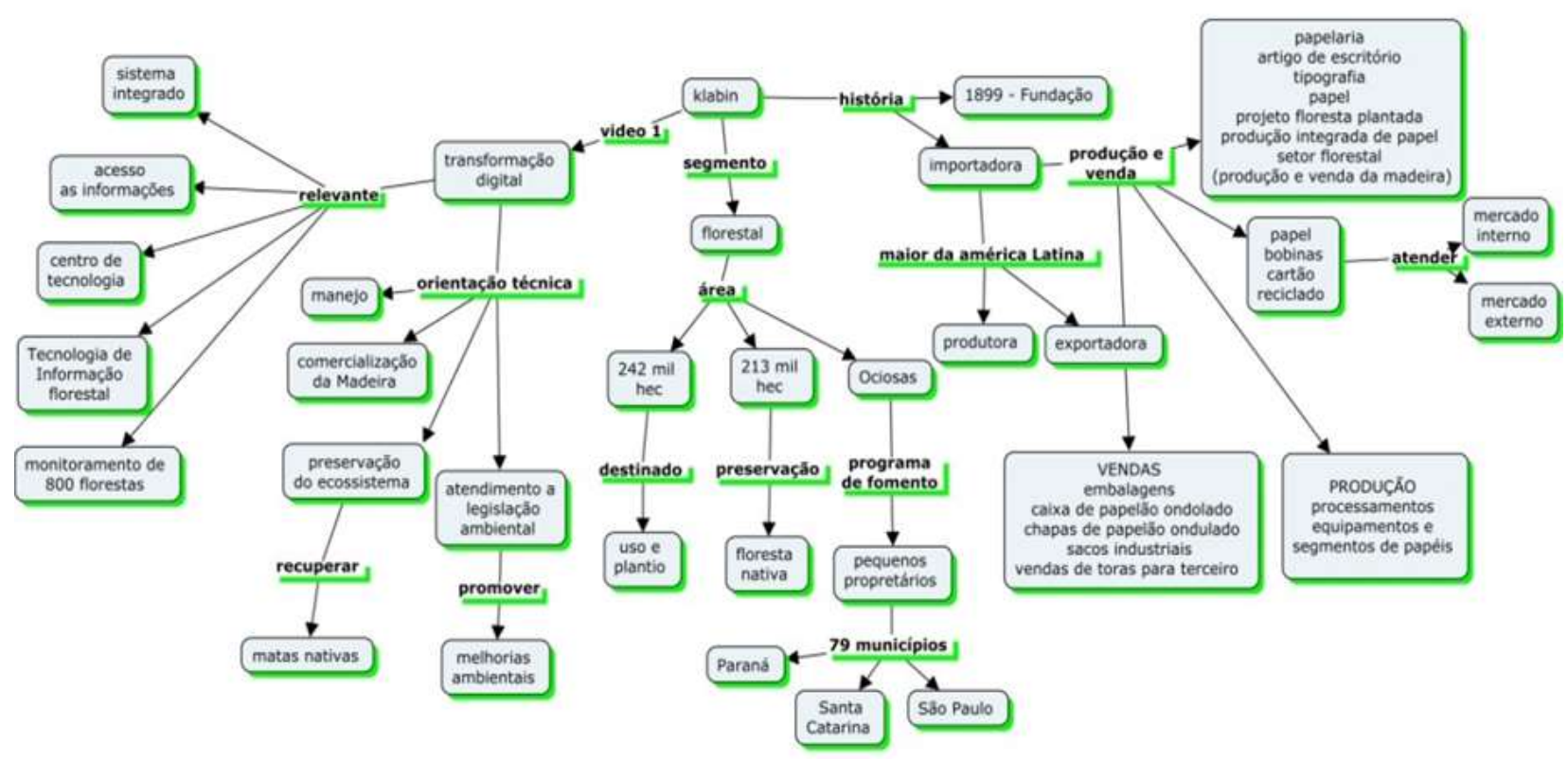

Fonte: Adaptado de Salotti et al., (2015).

A teoria dos atores dentro da silvicultura comunitária segundo Stanzel, krott e Schusserb (2020) abrange a pessoa individual, o proprietário de uma serraria, um ator coletivo, uma instituição governamental, desde que tenha influência sob uma floresta comunitária. A Klabin S.A conforme o mapa conceitual (Figura 1) apresenta a orientação técnica, área de abrangência florestal uso e plantio, preservação e programa de fomento (considerada áreas ociosas) abrangendo 79 municípios no Paraná, Santa Catarina e São Paulo. Fica evidente neste contexto, o conflito de interesses entre os atores sociais, políticos e econômicos.

Quadro 2. Mensuração do valor justo.

\begin{tabular}{|c|c|}
\hline \multicolumn{2}{|c|}{ Valor justo CPC 46 - Mensurações do Valor Justo (IFRS 13 Fair Value Measurement) } \\
\hline Análise de sensibilidade & Cálculo no nível 3 de qualidade da evidenciação da mensuração do valor justo. \\
\hline $\begin{array}{l}\text { Premissas utilizadas e taxas de } \\
\text { desconto }\end{array}$ & $\begin{array}{l}\text { A sensibilidade aos preços utilizados na avaliação e a taxa de desconto aplicado é o fluxo de } \\
\text { caixa descontado considerando o custo médio de capital levando em conta a taxa de Selic e } \\
\text { níveis de inflação. }\end{array}$ \\
\hline $\begin{array}{l}\text { Testes efetividade instrumento } \\
\text { de redge } \\
\text { accounting (derivativo). }\end{array}$ & $\begin{array}{l}\text { Testes de efetividade dentro dos critérios estabelecidos nos referidos pronunciamentos } \\
\text { contábeis, comparando as alterações do valor justo do instrumento de hedge com as alterações } \\
\text { do valor justo do objeto protegido em relação ao risco coberto. Caso a relação de hedge não se } \\
\text { demonstre efetiva dentro dos limites estabelecidos em relação à proteção desejada, a parcela } \\
\text { inefetiva dos efeitos de variação cambial sobre os empréstimos e financiamentos são } \\
\text { reclassificados para a demonstração do resultado sob a rubrica de "Resultado financeiro". }\end{array}$ \\
\hline $\begin{array}{l}\text { Test de impairment ou teste de } \\
\text { imparidade }\end{array}$ & $\begin{array}{l}4 \text { palavras: Na aplicação dos requisitos do CPC 01(R1) - Redução ao valor recuperável de } \\
\text { ativos (IAS } 36 \text { Impairment of Assets), efetuou as análises aplicáveis e não identificou } \\
\text { indicadores de que o valor contábil exceda o valor recuperável de seus ativos em } 30 \text { de junho } \\
\text { de } 2021 \text { e } 31 \text { de dezembro de } 2020 \text {. O teste aplicado no imobilizado da empresa. } \\
\text { Não ocorreu nenhuma provisão de perda necessidades de provisão para impairment no período } \\
\text { de seis meses ( } 30 \text { de junho de } 2021 \text { e no exercício findo em } 31 \text { de dezembro de 2020). }\end{array}$ \\
\hline 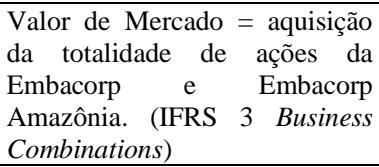 & $\begin{array}{l}\text { Relativos ao processo de combinação de negócios: valor de mercado e valor justo ajustado, } \\
\text { cujo valores de mercado foram abaixo do valor de mercado. }\end{array}$ \\
\hline $\begin{array}{l}\text { Nível }(1,2 \text { e } 3) \text { são proxies para } \\
\text { o comportamento oportuníssimo } \\
\text { dos gestores. }\end{array}$ & $\begin{array}{l}\text { Os títulos e valores mobiliários se enquadram no Nível } 1 \text { da hierarquia de mensuração pelo } \\
\text { valor justo, de acordo com a hierarquia do CPC } 46 \text { - Mensurações do Valor Justo (IFRS } 13 \\
\text { Fair Value Measurement), por tratar-se de ativos com preços cotados em mercado. }\end{array}$ \\
\hline $\begin{array}{l}\text { Julgamento } \\
\text { Ver nota explicativa } 28\end{array}$ & $\begin{array}{l}\text { CVM a Administração da Companhia analisou eventuais impactos por aumento de perdas } \\
\text { esperadas ou alteração significativa dos riscos que a Companhia está exposta frente as suas } \\
\text { estimativas, julgamentos e premissas que pudessem afetar a recuperabilidade dos seus ativos e }\end{array}$ \\
\hline
\end{tabular}




\begin{tabular}{|c|c|}
\hline & $\begin{array}{l}\text { a mensuração das provisões apresentadas nas referidas informações trimestrais. Esta revisão } \\
\text { considerou os eventos subsequentes ocorridos até a data de emissão destas informações } \\
\text { trimestrais e não foram identificados efeitos significativos que deveriam estar refletidos nas } \\
\text { informações trimestrais dos períodos de três e seis meses findos em } 30 \text { de junho de } 2021 \text {. }\end{array}$ \\
\hline Valor justo (subjetivo) & $\begin{array}{l}\text { A avaliação dos ativos biológicos por seu valor justo considera certas estimativas, tais como: } \\
\text { preço de madeira, taxa de desconto, plano de colheita das florestas e produtividade, cujas } \\
\text { variações geram efeitos não caixa nos resultados da Companhia. (informação relevante porque } \\
\text { impacta no caixa da empresa). }\end{array}$ \\
\hline Subjetivismo responsável & Nenhuma informação apresentada. \\
\hline $\begin{array}{l}\text { Custo } \\
\text { (objet }\end{array}$ & $\begin{array}{l}\text { Ativos biológicos } \\
\text { Saldo inicial } \\
\text { Adições e subtrações } \\
\text { 1. Plantio de madeira } \\
\text { 2. Alienação de ativos biológicos } \\
\text { Exaustão } \\
\text { 1. Custo histórico ajuste a valor justo } \\
\text { Variação do valor justo } \\
\text { Preço } \\
\text { Crescimento } \\
\text { Constituição de controlada } \\
\end{array}$ \\
\hline Dados observáveis & $\begin{array}{l}\text { Demais premissas, como o cronograma de vencimento dos passivos e taxas de juros utilizadas } \\
\text { no cálculo estão divulgadas em outros itens desta mesma nota explicativa, assim como os } \\
\text { índices de inflação são observáveis no mercado, de forma que os fluxos nominais possam } \\
\text { ser elaborados pelos usuários das informações trimestrais. }\end{array}$ \\
\hline $\begin{array}{l}\text { Conservadorismo, Relevância, } \\
\text { Confiança. }\end{array}$ & Nenhuma informação apresentada. \\
\hline Risco & $\begin{array}{l}\text { Hedge Accounting (proteção de fluxo de caixa da empresa); } \\
\text { Renda Fixa: duas emissões Green Bonds, cujos títulos devem necessariamente ter seus } \\
\text { recursos alocados em green projects elegíveis. }\end{array}$ \\
\hline $\begin{array}{l}\text { Parecer do auditor: } \\
\text { Auditoria: ERNST \& YOUNG } \\
\text { Auditores Independentes S.S. } \\
\text { CRC-2SP034519/O-6. }\end{array}$ & $\begin{array}{l}\text { Texto redacional do parecer dos auditores sem Ressalva, Apenas a DVA foi submetida à } \\
\text { revisão com o objetivo de saber se elas estão conciliadas com as informações trimestrais. } \\
\text { Observações dos auditores: "Com base em nossa revisão, não temos conhecimento de nenhum } \\
\text { fato que nos leve a acreditar que essas demonstrações do valor adicionado não foram } \\
\text { elaboradas, em todos os aspectos relevantes, segundo os critérios definidos nessa Norma e de } \\
\text { forma consistente em relação às informações contábeis intermediárias individuais e } \\
\text { consolidadas tomadas em conjunto". (KLABIN, 2021) }\end{array}$ \\
\hline Ativo & Descrito em custo histórico \\
\hline Segmento florestal & $\begin{array}{l}\text { Envolve as operações de plantio e cultivo florestal de pinus e eucalipto para abastecimento das } \\
\text { fábricas de papéis e celulose da Companhia e venda de madeiras (toras) para terceiros no } \\
\text { mercado interno. }\end{array}$ \\
\hline Atividade florestal & $\begin{array}{l}\text { No dia } 21.01 .2020 \text { foram celebrados os acordos necessários para associação com uma Timber } \\
\text { Investment Management Organization ("TIMO") para a constituição de uma Sociedade de } \\
\text { Propósito Específico ("SPE"), cujo objetivo principal é a exploração da atividade florestal no } \\
\text { centrosul do Estado do Paraná, permitindo o acesso a novas terras para o incremento de sua } \\
\text { base florestal. }\end{array}$ \\
\hline Produtos agrícolas & Nenhuma informação apresentada. \\
\hline $\begin{array}{l}\text { Ética/moral } \\
\text { Processo de natureza trabalhista }\end{array}$ & $\begin{array}{l}\text { Pedidos estão relacionados a horas extras, dano moral, adicional de insalubridade e } \\
\text { periculosidade, além de indenizações e responsabilidade subsidiária de terceiros. Nenhuma } \\
\text { ação individual é relevante o suficiente para impactar adversamente e de maneira relevante os } \\
\text { resultados da Companhia. }\end{array}$ \\
\hline
\end{tabular}

Fonte: Estudo de Caso Klabin: ITR - Informações Trimestrais - 30/06/2021 - Klabin S.A. (grifo nosso).

A variação do valor justo dos ativos biológicos resultou na receita de R \$ 199 milhões no segundo trimestre de 2021, principalmente pelo impacto do aumento do preço dos ativos biológicos (madeira em pé) obtido por meio de pesquisas de preço de mercado, divulgados por empresas especializadas. Já o efeito da exaustão do valor justo dos ativos biológicos (Quadro 2) no custo dos produtos vendidos foi de R $\$ 256$ milhões no mesmo período. Desta forma, o efeito não caixa do valor justo dos ativos biológicos no resultado operacional (EBIT) do 2T21 foi negativo em R \$ 57 milhões (Klabin, 2021).

Importante destacar que, além do segmento florestal a Klabin S.A apresenta outros segmentos: Segmento de Papéis: envolve substancialmente a produção e as operações de venda de bobinas de papel cartão, papel kraftliner e papel reciclado nos mercados internos e externos. Segmento de Conversão: envolve a produção e as operações de venda de caixas de papelão ondulado, chapas de papelão ondulado e sacos industriais, nos mercados interno e externo. Segmento de Celulose: envolve a produção e comercialização de celulose de fibra curta, longa e fluff nos mercados interno e externo (Klabin, 2021). 
Outros processos de natureza civil e ambiental: Ação Civil Pública proposta, em 2009, pela Associação dos Pescadores Ambientais do Paraná - APAP, em face de alegados danos ao Rio Tibagi (PR), pelo descarte de resíduos de carvão mineral queimado, utilizado pela Companhia até 1998. Apesar de não haver comprovação do dano ambiental, em dezembro de 2015 foi proferida sentença desfavorável à Companhia, condenando-a na obrigação de fazer a retirada do carvão mineral queimado depositado no leito do Rio. Atualmente, o processo está suspenso, conforme acordado entre as partes. Somente com o término da fase de liquidação será possível estipular o valor a ser considerado (Klabin, 2021 p.96 - 97).

Em relação ao gerenciamento de risco observar: risco de mercado, risco de aplicação de recursos, risco de crédito, risco de liquidez, análise de sensibilidade dentre outros (Klabin, 2021 p.63). Informações introduzidas pela empresa nas notas explicativas.

Figura 2. Ativos biológicos da Companhia Klabin S.A.

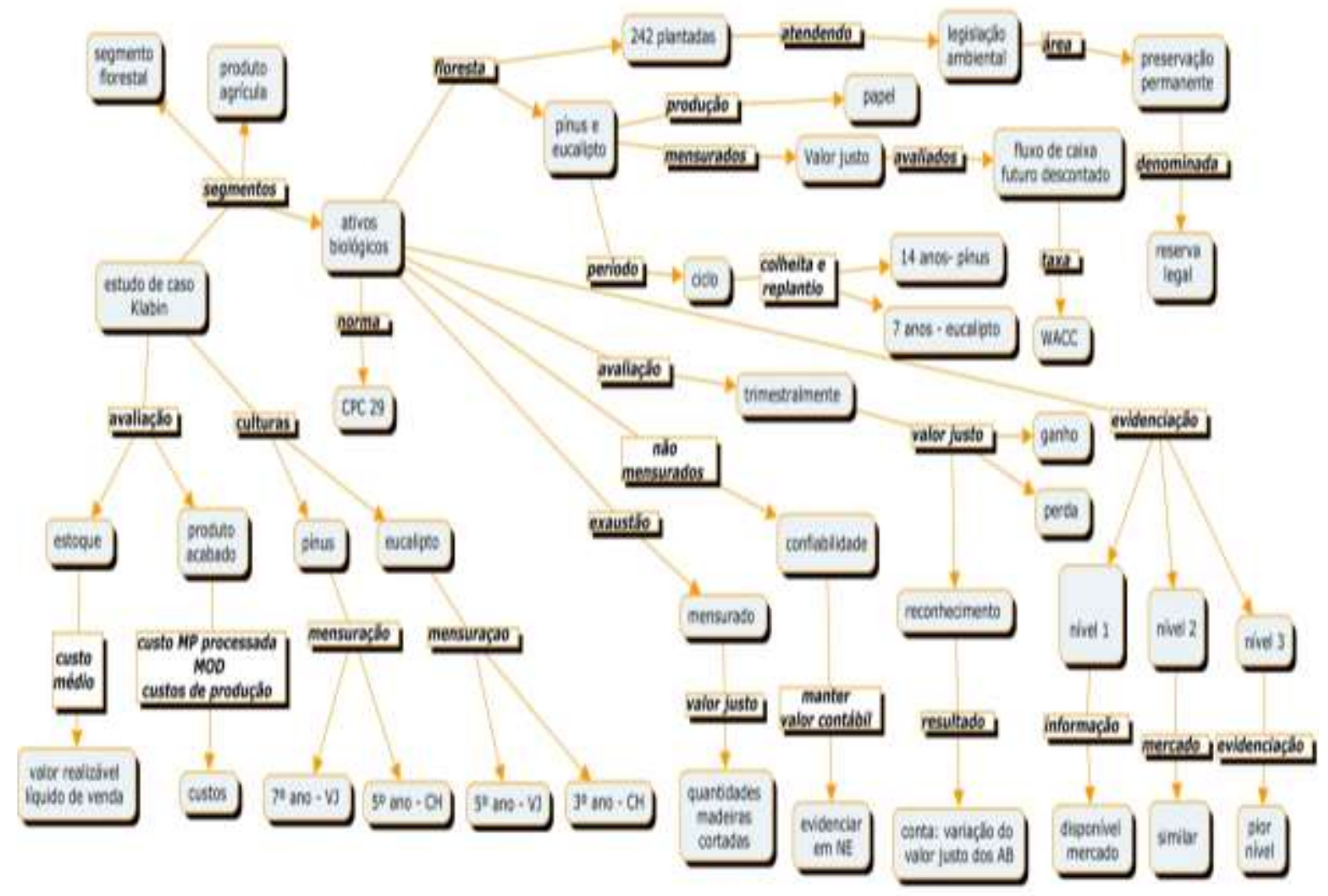

Fonte: Adaptado de Salotti et al., (2015).

Para a análise sistematizada documental de pagamento de serviços ambiental foram identificadas as palavras no texto da Lei (14.119/21) para possível análise de conteúdo do documento escrito. As seguintes palavras foram destacadas em conformidade com os conceitos de ambiente, questões ambientais, dano ambiental e projetos sociais: "Ecossistema", "manutenção" (trata de prevenção), "recuperação" (ação mitigadora), bens e produtos ambientais, decomposição dos resíduos (tratamento), Sequestro de carbono, Serviços culturais e Pagamento por serviços ambientais dentre outros (Quadro 4). No caso da legislação ambiental trata da reserva legal. 
Quadro 4. Pagamento de Serviço Ambiental.

\begin{tabular}{|c|c|}
\hline PSA - Texto da Lei 14.119/21 & Descrição da empresa objeto de estudo \\
\hline Ecossistema & Nenhuma informação apresentada \\
\hline Manutenção & $\begin{array}{l}16 \text { palavras: relacionadas a paradas de manutenção, manutenção de volume vendido (R\$1.705/t no } \\
\text { 2T2); Investimentos em manutenção operacional da Companhia (R\$185milhões); projetos especiais em } \\
\text { decorrência à pandemia (R\$ } 18 \text { milhões); Investimentos em: florestal, continuidade operacional, Capex } \\
\text { de manutenção, projetos especiais e projeto Puma II. }\end{array}$ \\
\hline Recuperação & $\begin{array}{l}3 \text { palavras: Grades de fibras. A Klabin, única Companhia brasileira a produzir três tipos de celulose } \\
\text { (fibra curta, fibra longa e fluff), se beneficia mais uma vez de seu portfólio diversificado. Termo } \\
\text { também relacionado ao Projeto de expansão - "Puma II". }\end{array}$ \\
\hline Bens e produtos ambientais & $\begin{array}{l}21 \text { palavras: Avanço na tendência de consumo de embalagens produzidas com matérias-primas } \\
\text { recicláveis, biodegradáveis e provenientes de fontes renováveis para produtos como farinha, açúcar, } \\
\text { café e ração animal. } \\
\text { Investimentos realizados em atividades de reflorestamento, restauração de matas nativas, investimentos } \\
\text { em energia renovável, logística eficiente com uso de transporte ferroviário, reciclagem de resíduos } \\
\text { sólidos e desenvolvimento de produtos ecoeficientes, dentre outras práticas de sustentabilidade. }\end{array}$ \\
\hline Decomposição de resíduos & $\begin{array}{l}2 \text { palavras: O recurso (Green Boom) é destinado às atividades de reflorestamento, restauração de matas } \\
\text { nativas, investimentos em energia renovável, logística eficiente com uso de transporte ferroviário, } \\
\text { reciclagem de resíduos sólidos e desenvolvimento de produtos ecoeficientes, dentre outras práticas de } \\
\text { sustentabilidade. Durante } 2020 \text { foi realizada a recompra de USD 9,5 milhões, alinhado a estratégia de } \\
\text { gestão de dívida da Companhia. } \\
\text { Ação Civil Pública (2009) pela Associação dos Pescadores Ambientais do Paraná - APAP, em danos ao } \\
\text { Rio Tibagi (PR), pelo descarte de resíduos de carvão mineral queimado, utilizado pela Companhia até } \\
\text { 1998. Observação: nenhuma palavra sobre decomposição. }\end{array}$ \\
\hline $\begin{array}{l}\text { Sequestro de carbono } \\
\text { Serviços culturais } \\
\text { Pagamento por serviços ambientais }\end{array}$ & $\begin{array}{l}\text { Nenhum texto apresentado. } \\
\text { Nenhum texto apresentado. } \\
\text { Nenhum texto apresentado. }\end{array}$ \\
\hline $\begin{array}{lll}\begin{array}{l}\text { Condições } \\
\text { ecossistemas }\end{array} & \text { ambientais } & \text { dos } \\
\end{array}$ & Nenhuma informação apresentada. As condições tratadas no texto são relativas ao mercado. \\
\hline $\begin{array}{l}\text { Certificado de reduções de emissões } \\
\text { por desmatamento e degradação }\end{array}$ & $\begin{array}{l}\text { No segundo trimestre a Klabin teve suas metas de redução de emissões de gases de efeito estufa (GEE) } \\
\text { aprovadas pela Science Based Targets initiative (SBTi). Nos últimos } 15 \text { anos a Companhia reduziu em } \\
60 \% \text { suas emissões de GEE e o compromisso assumido com a SBTi, fundamentado por critérios } \\
\text { científicos, representa uma contribuição ainda mais ambiciosa para a mitigação dos efeitos das } \\
\text { mudanças do clima, estabelecendo a redução das emissões de GEE por tonelada de celulose, papéis e } \\
\text { embalagens em } 25 \% \text { até } 2025 \text {, e em } 49 \% \text { até } 2035 \text {, tendo } 2019 \text { como ano-base. (ver melhor o relatório } \\
\text { de sustentabilidade). }\end{array}$ \\
\hline Títulos verde ou green bonds & $\begin{array}{l}\text { Duas palavras: "verde" tratando de verde vivo investimentos florestais LTDA representando } \\
\text { participações societárias em ações ordinárias. } \\
\text { Green bonds: A Companhia mantém cinco emissões ativas no mercado internacional (Notes ou Bonds). } \\
\text { Dentre esses, duas emissões Green Bonds, cujos títulos devem ser alocados em green projects elegíveis. } \\
\text { Além destes, há duas emissões convencionais de dívida. E por último, um Sustainability Linked Bonds } \\
\text { (SLB), cujo cupom é atrelado aos indicadores de performance em Sustentabilidade }\end{array}$ \\
\hline Comodato & Nenhum texto apresentado. \\
\hline Cota de reserva ambiental & $\begin{array}{l}\text { Em } 30 \text { de junho de } 2021 \text { a Companhia possui } 271 \text { mil hectares }(267 \text { mil hectares em } 31 \text { de dezembro de } \\
\text { 2020) de florestas plantadas, desconsiderando as áreas de preservação permanente e reserva legal que } \\
\text { devem ser mantidas para atendimento à legislação ambiental brasileira. }\end{array}$ \\
\hline Vegetação nativa & $\begin{array}{l}\text { Em setembro de } 2017 \text { a Companhia emitiu Green Bonds no valor de USD } 500 \text { milhões, com prazo de } \\
10 \text { anos vencimento em } 2027 \text {, com cupom semestral de } 4,88 \% \text {. O recurso é destinado às atividades de } \\
\text { reflorestamento, restauração de matas nativas, investimentos em energia renovável, logística eficiente } \\
\text { com uso de transporte ferroviário, reciclagem de resíduos sólidos e desenvolvimento de produtos } \\
\text { ecoeficientes, dentre outras práticas de sustentabilidade. Durante } 2020 \text { foi realizada a recompra de USD } \\
9,5 \text { milhões, alinhado a estratégia de gestão de dívida da Companhia. }\end{array}$ \\
\hline Desenvolvimento sustentável & Desenvolvimento de produtos ecoeficientes. \\
\hline Qualidade de vida & Nenhuma informação apresentada. Os temos encontrados estão relacionados à qualidade da informação. \\
\hline Biomas & Nenhum texto apresentado. \\
\hline Legislação ambiental & Citação relativa à reserva legal. \\
\hline $\begin{array}{l}\text { Inclusão socioeconômica e a } \\
\text { regularização ambiental de } \\
\text { populações rurais em situação de } \\
\text { vulnerabilidade. }\end{array}$ & $\begin{array}{l}\text { Termo inclusão relativo a ativo. } \\
\text { Regularização ambiental = nenhum texto apresentado. } \\
\text { Populações rurais = nenhum texto apresentado. } \\
\text { Vulnerabilidade = nenhum texto apresentado. }\end{array}$ \\
\hline $\begin{array}{l}\text { Formação de corredores de } \\
\text { biodiversidade } \\
\text { Conservação de recursos hídricos } \\
\text { Comunidades, povos indígenas, } \\
\text { agricultores familiares e } \\
\text { empreendedores rurais }\end{array}$ & $\begin{array}{l}\text { Nenhum texto apresentado. } \\
\text { Nenhum texto apresentado. } \\
\text { Nenhum texto apresentado. }\end{array}$ \\
\hline $\begin{array}{l}\text { Financiamentos e agências bilaterais } \\
\text { e multilaterais }\end{array}$ & $\begin{array}{l}\text { Financiamentos vinculados à execução do Projeto Puma II, contratados, e parcialmente desembolsados } \\
\text { nos seguintes montantes a serem sacados: (i) BID Invest, IFC e JICA, US\$ } 700 \text { milhões; Finnvera, US\$ } \\
178 \text { milhões; (iii) BNDES, R\$ } 2 \text { bilhões. Esses financiamentos poderão ser sacados, total ou } \\
\text { parcialmente, conforme o andamento do Projeto Puma II e/ou necessidade de caixa da Companhia. } \\
\text { Agências relativas aos riscos. }\end{array}$ \\
\hline $\begin{array}{l}\text { Conservação de áreas urbanas, } \\
\text { periurbanas e } \\
\text { Qualidade do ar }\end{array}$ & $\begin{array}{l}\text { Nenhum texto apresentado. } \\
\text { Nenhum texto apresentado. }\end{array}$ \\
\hline
\end{tabular}

Fonte: Adaptado Klabin - ITR, agosto (2021). 
O projeto puma II ${ }^{1}$ é um marco no ciclo de expansão da Klabin, o que reforça sua capacidade de crescimento sustentável aliada à tecnologia, investimentos em pesquisa, inovação e tecnologia em todas as etapas: energia limpa, gestão inteligente de resíduos, tratamento de efluentes, emissões atmosféricas e de ácido sulfúrico.

Figura 3. Projeto Puma II- Rio De Janeiro.

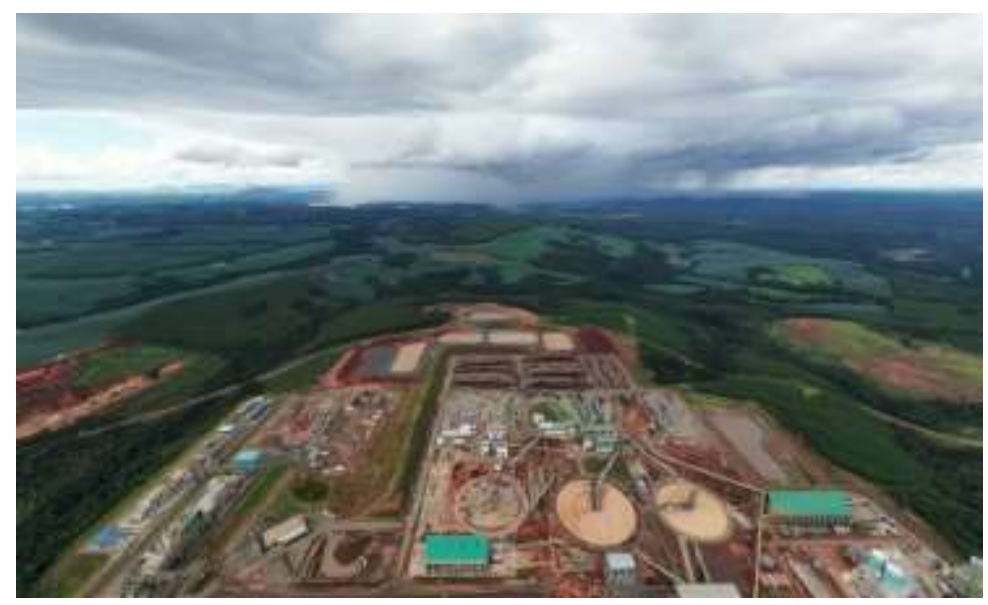

Fonte: https://www.youtube.com/watch?v=kuaeckrue_0

Projeto Puma II, Rio de Janeiro (Figura 3) dispõe de uma ampla estrutura industrial: pátio de estocagem de toras, descascadores e picadores, estocagem de cavacos, estocagem de biomassa, caustificação e forno de cal, planta de gaseificação de biomassa, torres de resfriamento da evaporação, ETAC, Evaporação, linhas de fibras, celulose marron, Caldeira de força e recuperação, pipe rack, ETA, ETE, prédios auxiliares, ampliação da central de resíduos sólidos, pátio externo de expedição de containers, máquina kraftliner MP-27.

Figura 4. Caldeira de Recuperação e Caldeira de Força.

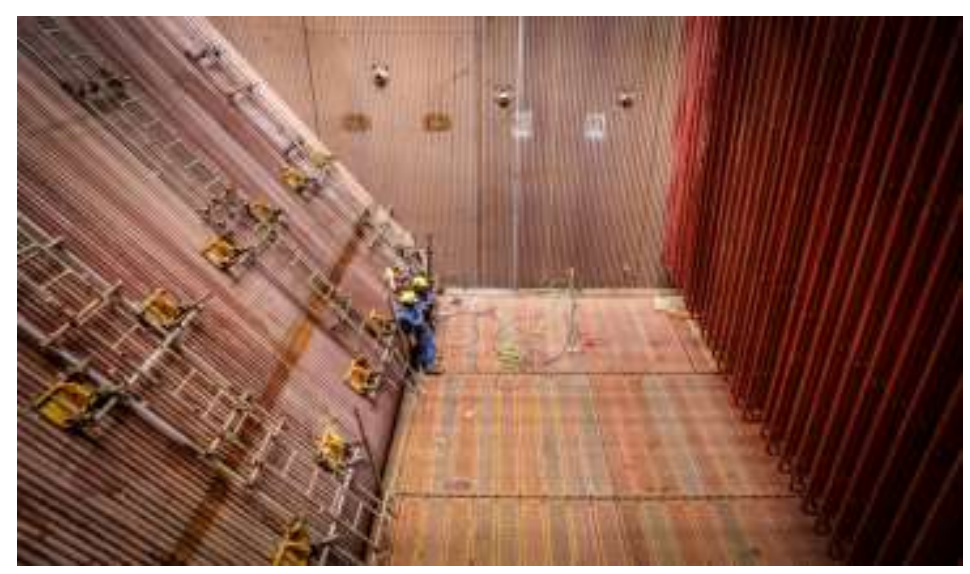

Fonte: https://projetopuma.klabin.com.br/group/puma/-/caldeira-de-recupera\%C3\%A7\%C3\%A3o-est\%C3\%A1-pronta-paraopera $\% \mathrm{C} 3 \% \mathrm{~A} 7 \% \mathrm{C} 3 \% \mathrm{~A} 3 \mathrm{o}-$

\footnotetext{
${ }^{1}$ A Empresa Klabin S.A criou o Projeto Puma, e o nome faz analogia ao Puma que é o felino com distribuição geográfica mais ampla pelas terras do hemisfério ocidental. Similar ao animal que leva o seu nome, o Projeto Puma II é caracterizado pela grandeza de sua presença. Na visão da empresa este é o maior investimento da história da Klabin. O complexo industrial localizado em Ortigueira, no Paraná, terá duas etapas de expansão até 2023, contando com a construção de duas inovadoras máquinas de papel. O projeto fará da Klabin a primeira empresa do mundo a produzir o papel Eukaliner, do qual já possui a patente. Junto ao Eukaliner White, os papéis exigem menos gasto energético para serem produzidos e possuem resultados até $20 \%$ superiores que os atuais produtos do mercado. Projeto Puma II. Recuperado de https://projetopuma.klabin.com.br/\#conheca.
} 
A etapa da produção (Figura 4) retrata a caldeira de recuperação que representa a primeira queima de licor preto (resultado do cozimento das fibras de celulose), considerado o marco mais importante da planta. A geração de energia a partir da queima do licor gerado no cozimento da madeira, reforça a condição de fábrica sustentavelmente viável e autossuficiente.

Figura 5. Lateral de linhas de vibras.

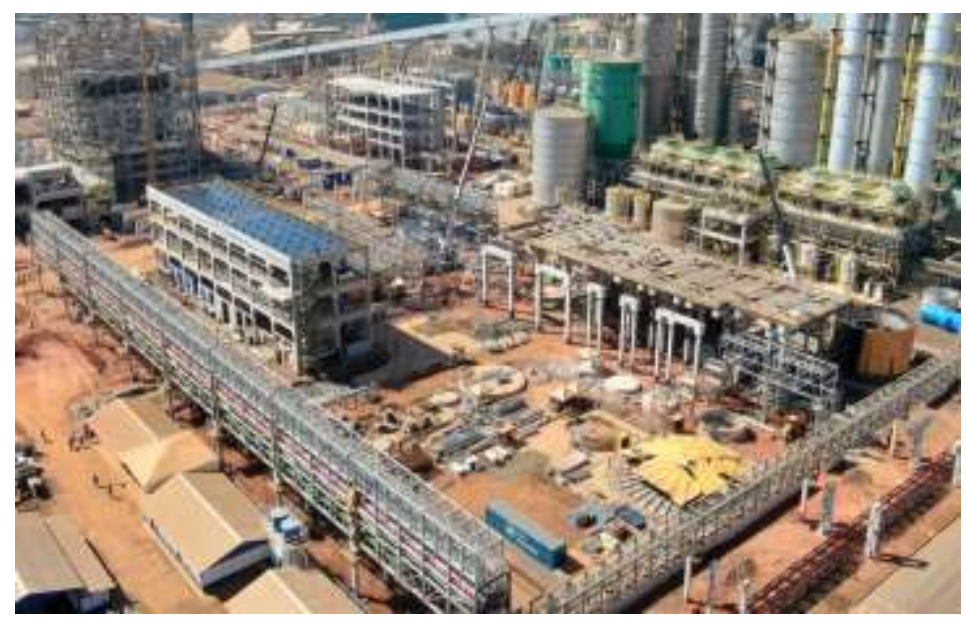

Fonte: klabin.com.br/negocios-e-produtos/celulose

A empresa objeto de estudo é a única no Brasil a produzir e fornecer três diferentes tipos de celulose: fibra curta (eucalipto), fibra longa (pínus) e fluff, fabricadas em uma única unidade industrial (Figura 5). As celuloses são provenientes de florestas $100 \%$ plantadas com certificações globalmente reconhecidas que abrangem desde a madeira até o produto final, garantindo a sustentabilidade e a segurança do começo ao fim do processo.

Figura 6. Estação de Tratamento de Efluentes - ETE.

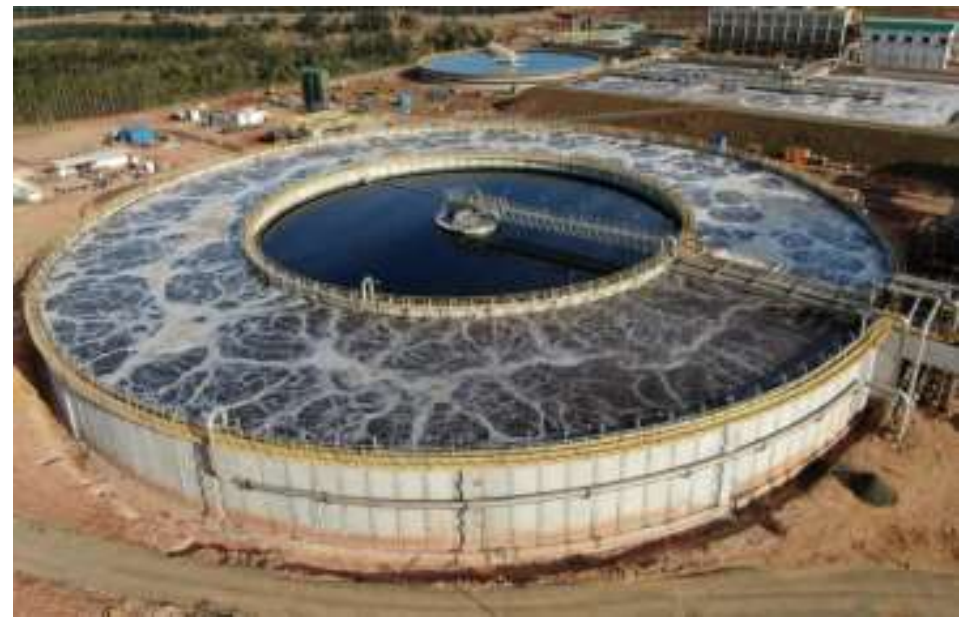

Fonte: https://projetopuma.klabin.com.br/group/puma/-/iniciando-os-trabalhos-da-ete

Estação de Tratamento de Efluentes - ETE dando sequência à alimentação do efluente bruto, passando pelo gradeamento, clarificador primário, torre de resfriamento, reator biológico, clarificador secundário e tratamento terciário (Figura 6). Com o maior tanque de processo da América Latina, o tanque de aeração tem um volume de $70.000 \mathrm{~m}^{3}$ que equivale a aproximadamente três piscinas olímpicas. A ETE vai tratar 100\% dos efluentes que serão gerados após a partida. São exatamente $2700 \mathrm{~m}^{3} / \mathrm{h}$ de efluentes. 
Em relação ao passivo ambiental, existe uma Ação Civil Pública (2009) pela Associação dos Pescadores Ambientais do Paraná - APAP, em danos ao Rio Tibagi (PR), pelo descarte de resíduos de carvão mineral queimado, utilizado pela Companhia até 1998. Apesar de não haver comprovação do dano ambiental, em dezembro de 2015 foi proferida sentença desfavorável à Companhia, condenando-a na obrigação de fazer a retirada do carvão mineral queimado depositado no leito do Rio. Atualmente, o processo está suspenso, conforme acordado entre as partes. Somente com o término da fase de liquidação será possível estipular o valor a ser considerado (Klabin - ITR, 2021).

No que diz respeito à palavra pagamento, trata-se especificamente sobre juros, empréstimos, financiamento, debêntures, passivos em arrendamentos, pagamentos de dividendos, pagamento de royalties referentes a tais marcas, pagamento de participação em sociedade, dentre outros, não mencionando serviços de pagamentos ambientais. É importante destacar que, a avaliação dos ativos biológicos por seu valor justo, considera certas estimativas, tais como: preço de madeira, taxa de desconto, plano de colheita das florestas e volume de produtividade, as quais estão sujeitas a incertezas, podendo gerar efeitos nos resultados futuros em decorrência de suas variações (Klabin - ITR, 2021).

Sobre os gases efeitos estufas (GEE) no segundo trimestre a Klabin teve suas metas de redução de emissões aprovadas pela Science Based Targets Initiative (SBTi). Nos últimos 15 anos a Companhia reduziu em 60\% suas emissões de GEE e o compromisso assumido com a SBTi, fundamentado por critérios científicos, representa uma contribuição para a mitigação dos efeitos das mudanças do clima, estabelecendo a redução das emissões de GEE por tonelada de celulose, papéis e embalagens em 25\% até 2025, e em 49\% até 2035, tendo 2019 como ano-base (Klabin- ITR, 2021).

Até o presente momento a Administração da Companhia não identificou impactos significativos em suas operações, mantendo suas previsões de produção, vendas e expedição de seus produtos, dos quais fazem parte da cadeia de abastecimento de itens de primeira necessidade para a população (Klabin - ITR, 2021).

\section{Considerações Finais}

Os resultados deste estudo apresentam aspectos relevantes sobre a qualidade da informação financeira em relação à informação não financeira (informação ambiental). A análise realizada apresenta a diversidade textual entre o arcabouço conceitual do valor justo, valor de mercado e Pagamento de Serviço Ambiental.

Neste sentido o objetivo desta pesquisa foi compreender qual o alinhamento tipológico aplicada nos textos da Lei 14.119/21 em relação ao arcabouço teórico sobre a norma IFRS que trata de valor justo: Valor justo CPC 46 - Mensurações do Valor Justo (instrumentos financeiros); IFRS 13 Fair Value Measurement e Ativos biológicos (plantas e animais) CPC 29 IAS 41.

Foi realizada a análise documental no texto da Lei de pagamento de serviços ambientais e do relatório trimestral (ITR, 2021) de uma empresa potencialmente poluidora do segmento de papel e celulose. Com os resultados do estudo foram possíveis analisar que aspectos relativos à informação financeira (valor justo e valor de mercado) não é apresentado no texto redacional da Lei supracitada.

Observa que a Lei de Pagamento de Serviços Ambientais delineia aspectos relevantes das questões ambientais em detrimento das informações financeiras (valor justo e valor de mercado). Acredita-se que estas informações do PSA estarem mais presente no relatório de sustentabilidade. Relevante destacar as informações ambientais diante dos aspectos relacionados no conteúdo dos relatórios analisados frente o desenvolvimento sustentável.

Para artigos ou trabalhos futuros uma das sugestões é de continuidade de pesquisas de estudos de casos das divulgações ambientais analisando as premissas existentes nesta pesquisa: valor justo, valor de mercado, ativos biológicos e Lei 14.119/21. Outros temas devem ser observados para trabalhos futuros: passivo ambiental, conservação de recursos hídricos comunidades, povos indígenas, agricultores familiares e empreendedores rurais. 
Research, Society and Development, v. 10, n. 15, e184101523944, 2021

(CC BY 4.0) | ISSN 2525-3409 | DOI: http://dx.doi.org/10.33448/rsd-v10i15.23944

\section{Referências}

Barankievicz, V. A., Maria Sobrinho, R. F., \& Fernandes, B. H. R. (2016). A Floresta Encantada que Transforma Realidades: O Caso da Klabin S/A. Tecnologias de Administração e Contabilidade, 6(2), 111-132.

Braga, R., de Sousa, E. P., \& Alves F', E. M. (2014). Mensuração a valor justo no Brasil: análise da produção científica de 2006 a 2012 . Revista de Contabilidade da UFBA, 8(2), 47-63. https://www.researchgate.net/publication/275334705

Caldeira de Recuperação e Caldeira de Força. https://projetopuma.klabin.com.br/group/puma/-/caldeira-de-recupera\%C3\%A7\%C3\%A3o-est\%C3\%A1-prontapara-opera\%C3\%A7\%C3\%A3o-

Carson, R. (2010). Primavera silenciosa. São Paulo. Editora Gaia.

Comitê de pronunciamentos contábeis - CPC. Pronunciamento Técnico CPC 29 - Ativo Biológico e Produto Agrícola. Resolução CFC nº 1.186/09 e alterações posteriores. http://www.cpc.org.br/index.php.

Estação de Tratamento de Efluentes - ETE. https://projetopuma.klabin.com.br/group/puma/-/iniciando-os-trabalhos-da-ete

Hendriksen, E. S., \& Van Breda, M. F. (1999). Teoria da contabilidade; tradução de Antonio Zoratto Sanvicente. São Paulo: Atlas, $277-297$.

IBAMA (2015). Tabela de atividades potencialmente poluidoras e utilizadoras de recursos ambientais. https://abapa.com.br/wpcontent/uploads/2015/03/tabela.pdf

Iudicibus, S. Martins, E. (2007). Uma investigação e uma proposição sobre o conceito e o uso do valor justo. Revista Contabilidade e Finanças, p. 9-18.

Klabin (2021, agosto).

Informações Trimestrais Klabin S.A. https://api.mziq.com/mzfilemanager/v2/d/1c41fa99-efe7-4e72-81dd-5b571f5aa376/a33b5103-da02-d4fe-48bf81e32287edfb?origin=2.

Lateral de linhas de vibras. klabin.com.br/negocios-e-produtos/celulose.

Lei $\mathrm{n}^{\circ}$ 14.119, de 13 de janeiro de 2021 Institui a Política Nacional de Pagamento por Serviços Ambientais; e alteram as Leis n os 8.212, de 24 de julho de 1991, 8.629, de 25 de fevereiro de 1993, e 6.015, de 31 de dezembro de 1973, para adequá-las à nova política. https://www.in.gov.br/en/web/dou/-/lei-n14.119-de-13-de-janeiro-de-2021-298899394.

Lemes, S., Campos, L. C., Alves, R. D. S., \& de Almeida, N. S. (2016). Casos para Ensino em Contabilidade Societária. (1 ed). São Paulo: Atlas.

Lopes, A. B. \& Martins, E. (2005). Teoria da contabilidade: uma nova abordagem. Atlas.

Marques, T. O., Schultz, C. A., Dandolini, G. A., \& Petri, S. M. (2012). Valor justo aplicado nos instrumentos financeiros: um estudo nas pesquisas nacionais e internacionais. Revista Contabilidade e Controladoria, 4(2).

Martins, E. (2000). Avaliação de empresas: da mensuração contábil à econômica. Caderno de estudos, 13(24), 28-37.

Melo, M. F. S.; Neves, A. I. P.; Luz, J. R. M. (2019). Capítulo 5: Evidenciação da companhia abertas de madeira, papel e celulose no Brasil em 2017. In: Pesquisa em contabilidade: enfoque empresarial, social e controle.01 ed.São Paulo: Novas edições acadêmicas. V.01, p. 01-409.

Menezes, B. N. C., Santos, M. F. B., Moreira, F. N. \& Szuster, N. (2011)Valor Justo: O Impacto da Lei No $11.638 / 07$ na Pesquisa Brasileira em Contabilidade. Anais do $V$ Congresso da Associação Nacional de Programas de Pós Graduação em Ciências Contábeis - ANPCONT. Recuperado de https://anpcont.org.br/pdf/2011/EPC269.pdf.

Projeto Puma II - Rio De Janeiro. Recuperado de https://www.youtube.com/watch?v=kuaeckrue_0

Richardson, R. J. (2009). Pesquisa social: método e técnicas. (3ºd). São Paulo: Atlas.

Salotti, B. M., Murcia, F. D.R., Carvalho, N. \& Flores, E. (2015). IFRS no Brasil: Temas avançadas abordados por meio de casos reais. São Paulo: Atlas.

Stanzel, J., Krott, M., \& Schusser, C. (2020). Power alliances for biodiversity-Results of an international study on community forestry. Land Use Policy, 97, 102963.

Sunder, S. (2014). Teoria da contabilidade e do controle. São Paulo: Atlas.

Transformação digital na Klabin - Caso de Sucesso. https://www.youtube.com/watch?v=LYMt81VeYTw.

Yin, R. K. (2010). Estudo de Caso: Planejamento e Métodos. (4.ed.) Porto Alegre: Book. 